\title{
METODE BAYES UNTUK DISTRIBUSI RAYLEIGH PADA DATA TAHAN HIDUP DISENSOR TIPE II
}

\author{
SILVIA YUNANDA, FERRA YANUAR, HAZMIRA YOZZA \\ Program Studi S1 Matematika, \\ Fakultas Matematika dan Ilmu Pengetahuan Alam, Universitas Andalas, \\ Kampus UNAND Limau Manis Padang, Indonesia. \\ email : silviayunanda2015@gmail.com
}

Diterima 14 Oktober 2019 Direvisi 21 Oktober 2019 Dipublikasikan 3 Desember 2019

\begin{abstract}
Abstrak. Analisis ketahanan hidup (survival) merupakan analisis statistika yang digunakan untuk menganalisis ketahanan hidup atau keandalan suatu komponen atau objek. Dalam melakukan analisis ketahanan hidup, dibutuhkan data tahan hidup yang meliputi waktu tahan hidup dan status waktu tahan hidup dari komponen atau objek yang diteliti.Pada data disensor tipe II, pengamatan berakhir sampai $r$ buah dari $n$ objek yang diteliti $(r<n)$ telah mati, sehingga masih terdapat $n-r$ objek yang masih tetap hidup. Distribusi Rayleigh dapat digunakan untuk menggambarkan prilaku peluang dari daya tahan hidup. Metode Bayes adalah suatu metode estimasi yang didasarkan pada penggabungan informasi yang diperoleh dari sampel (pengetahuan obyektif) dengan informasi lain yang telah tersedia sebelumnya (pengetahuan subyektif) mengenai parameter yang akan diduga. Diperoleh estimator Bayes dari parameter berdistribusi Rayleigh untuk data disensor tipe II adalah $(\widehat{\lambda})=\frac{r}{\sum_{i=1}^{r}\left(t_{i}^{2}\right)+\left(t_{r}^{2}\right)(n-r)}$ dengan fungsi hazard adalah $h(t)=2\left(4,3 \times 10^{-6}\right) t$ dan fungsi survival adalah $S(t)=\exp \left(-\left(4,3 \times 10^{-6}\right) t^{2}\right)$.
\end{abstract}

Kata Kunci: Metode Bayes, Distribusi Rayleigh, Data Disensor Tipe II.

\section{Pendahuluan}

Analisis ketahanan hidup (survival) merupakan analisis statistika yang digunakan untuk menganalisis ketahanan hidup atau keandalan suatu komponen atau objek. Keandalan suatu komponen atau objek adalah peluang tidak terjadinya kerusakan suatu alat untuk melakukan fungsinya secara wajar pada periode waktu yang ditentukan.

Dalam melakukan analisis ketahanan hidup, dibutuhkan data tahan hidup yang meliputi waktu tahan hidup dan status waktu tahan hidup dari komponen atau objek yang diteliti. Data ketahanan hidup yang diperoleh dari percobaan uji hidup dapat berbentuk data lengkap, data disensor tipe I atau data disensor tipe II. Pada data disensor tipe II, pengamatan berakhir sampai $r$ buah dari $n$ objek yang diteliti $(r<n)$ telah mati. Dengan metode ini, pasti akan diperoleh $r$ data daya tahan hidup dengan biaya yang relatif lebih sedikit dibandingkan data lengkap. Kelemahannya, waktu yang diperlukan untuk memperoleh $r$ objek yang mati bisa jadi sangat panjang. 
Distribusi Rayleigh merupakan salah satu bentuk khusus dari Distribusi Weibull, dimana distribusi ini merupakan Distribusi Weibull dengan parameter $\beta=2$. Peubah acak X yang berditribusi Rayleigh biasa dilambangkan dengan $\mathrm{X} \sim \operatorname{Rayleigh}(\lambda)$, dengan $\lambda$ adalah parameter distribusi yang menyatakan rata-rata daya tahan hidup.

Metode Bayes adalah suatu metode estimasi yang didasarkan pada penggabungan informasi yang diperoleh dari sampel dengan informasi lain yang telah tersedia sebelumnya mengenai parameter yang akan diduga. Informasi mengenai parameter dinyatakan dalam sebuah distribusi yang dinamakan distribusi prior. Distribusi prior ini selanjutnya digabungkan dengan distribusi sampel untuk menghasilkan suatu distribusi parameter baru yang dinamakan distribusi posterior. Distribusi posterior inilah yang selanjutnya akan digunakan untuk mengestimasi parameter yang akan diduga.

Distribusi prior dibagi menjadi dua yaitu distribusi prior informatif dan distribusi prior noninformatif. Distribusi prior informatif digunakan jika terdapat informasi atau asumsi tertentu mengenai sebaran prior dari parameter tersebut. Jika tidak ada informasi yang dapat digunakan untuk menyatakan distribusi priornya, digunakan distribusi prior noninformatif, yaitu sebuah prior tanpa keterangan parameter. Salah satu distribusi prior noninformatif yang dapat digunakan adalah distribusi prior yang diperoleh dengan metode Jeffrey [9].

Selain fungsi distribusi data tahan hidup, fungsi-fungsi lain yang biasa digunakan dalam menggambarkan prilaku ketahanan hidup suatu komponen adalah fungsi survival dan fungsi hazard.

Beberapa penelitian telah dilakukan untuk mengestimasi parameter dari distribusi Rayleigh pada data ketahanan hidup disensor tipe II. Diantaranya Sunandar pada tahun 2006 yang menggunakan metode maximum likelihood untuk mengestimasi parameter sebaran dari data waktu hidup disensor tipe II yang berdistribusi Rayleigh [6]. Widiharih dan Mardiyati pada tahun 2008 menggunakan metode maximumlikelihood untuk mengestimasi parameter titik dan metode besaran pivot untuk mengestimasi parameter interval dari data waktu hidup tersensor tipe II yang berdistribusi Rayleigh [8].

Penelitian yang telah dilakukan tersebut menggunakan metode maximum likelihood untuk mengestimasi parameternya. Dengan metode ini, parameter populasi diasumsikan tetap walaupun nilainya tidak diketahui. Pada metode maximum likelihood, teknik estimasi parameternya lebih mudah sehingga teknik ini sering digunakan. Akan tetapi teknik ini hanya dapat digunakan bilamana distribusi populasi diketahui. Selain itu, metode maximum likelihood ini sangat sensitif terhadap data ekstrim atau data pencilan. Data pencilan ini sangat berpengaruh terhadap nilai rata-rata dan variansi. Karena kekurangan yang dimiliki metode maximum likelihood, maka digunakan metode lain untuk mengestimasi parameter yakni metode Bayes. 


\section{Landasan Teori}

\subsection{Teorema Bayes}

Teorema 2.1. (Teorema Bayes) [7] Jika kejadian $B_{1}, B_{2}, \cdots, B_{k}$ merupakan suatu partisi ruang sampel $S$ dengan $P\left(B_{j}\right) \neq 0$ untuk $j=1,2, \cdots, k$, maka untuk setiap kejadian $A$ dalam $S$ sedemikian sehingga $P(A) \neq 0$ berlaku

$$
P\left(B_{j} \mid A\right)=\frac{P\left(A \mid B_{j}\right) P\left(B_{j}\right)}{\sum_{i=1}^{k} P\left(A \mid B_{i}\right) P\left(B_{i}\right)}
$$

untuk $j=1,2, \cdots, k$.

\subsection{Distribusi Rayleigh}

Peubah acak adalah fungsi yang memetakan anggota dari suatu percobaan ke himpunan bilangan riil peubah acak Rayleigh. Distribusi Rayleigh merupakan Distribusi Weibull dengan parameter skala $\beta=2$. Fungsi kepekatan peluang dari peubah acak $\mathrm{T}$ yang berdistribusi Rayleigh dengan parameter $\lambda$ dapat ditulis $\mathrm{T} \sim \operatorname{Rayleigh}(\lambda)$ adalah [8]

$$
f(t)=2 \lambda t \exp \left(-\lambda t^{2}\right)
$$

dengan $\lambda, t>0$

\subsection{Analisis Ketahanan Hidup}

Analisis ketahanan hidup merupakan salah satu analisa statistik yang menganalisis tentang daya tahan hidup atau keandalan suatu komponen atau objek pada keadaan tertentu. Ada tiga macam percobaan uji hidup yang sering digunakan dalam eksperimen ketahanan hidup, masing-masingnya menghasilkan data sampel sebagai berikut [8]: data sampel lengkap, data disensor tipe I dan data disensor tipe II.

Fungsi survival dapat dinotasikan dengan $S(t)$ adalah fungsi yang menyatakan peluang suatu individu bertahan hidup lebih dari waktu $t$. Fungsi survival dinyatakan sebagai [5]

$$
S(t)=1-F(t) .
$$

Fungsi ini didefinisikan sebagai kelajuan suatu individu untuk mengalami kegagalan pada interval waktu $t$ sampai $(t+\Delta t)$ apabila diketahui individu tersebut belum mengalami kegagalan sampai dengan waktu $t$. Secara matematis, fungsi hazard dapat dituliskan sebagai [5]

$$
h(t)=\frac{f(t)}{S(t)}
$$

\subsection{Statistika Tataan Penarikan Sampel}

Teorema 2.2. Fungsi kepekatan peluang marjinal bersama dari $r$ statistika tataan pertama dari contoh acak berukuran $n$ yang berasal dari suatu fungsi kepekatan peluang kontinu $f(x)$ diberikan oleh [1]

$$
g\left(y_{1}, y_{2}, \cdots, y_{r}\right)=\frac{n !}{(n-r) !}\left(1-F\left(y_{r}\right)\right)^{n-r} \prod_{i=1}^{r} f\left(y_{i}\right)
$$




\subsection{Metode Estimasi Bayes}

\subsubsection{Fungsi Likelihood}

Definisi 2.3. [1] Fungsi kepekatan peluang dari n peubah acak $X_{1}, X_{2}, \cdots, X_{n}$ yang dihitung pada $x_{1}, x_{2}, \cdots, x_{n}$ dinyatakan oleh $f\left(x_{1}, x_{2}, \cdots, x_{n} ; \theta\right)$ dirujuk oleh fungsi likelihood. Untuk $x_{1}, x_{2}, \cdots, x_{n}$ yang ditetapkan, fungsi likelihood adalah fungsi dari parameter $\theta$ dinotasikan oleh $L(\theta)$. Jika $X_{1}, X_{2}, \cdots, X_{n}$ menyatakan contoh acak dari distribusi $f(x ; \theta)$, maka :

$$
L(\theta)=\prod_{i=1}^{n} f\left(x_{i} ; \theta\right) .
$$

\subsubsection{Distribusi Prior}

Terdapat beberapa tipe distribusi prior, berkaitan dengan bentuk distribusi hasil identifikasi pola datanya distribusi prior dibagi menjadi dua bagian yaitu [3] :

(1) Distribusi prior konjugat.

(2) Distribusi prior non-konjugat.

Berkaitan dengan informasi yang terkait dengan penentuan masing-masing parameter, distribusi prior dibagi menjadi dua bagian yaitu :

(1) Distribusi prior informatif.

(2) Distribusi prior non-informatif.

\subsubsection{Distribusi Posterior}

Fungsi kepekatan peluang posterior dari $\theta$ jika diketahui sampel pengamatan $x_{1}, x_{2}, \cdots, x_{n}$ adalah [6]:

$$
f(x \mid \theta)=\frac{f(x \mid \theta) f(\theta)}{\int f(x \mid \theta) f(\theta) d \theta} \propto f(x \mid \theta) f(\theta)
$$

\subsubsection{Metode Jeffrey}

Metode Jeffrey merupakan salah satu pendekatan prior noninformatif. Dengan aturan Jeffrey, distribusi prior noninformatif untuk suatu parameter tunggal $\theta$ dari suatu sebaran peubah acak $X$ dinyatakan sebagai [2]:

$$
g(\theta)=\sqrt{I(\theta)}
$$

\section{Data dan Hasil}

\subsection{Distribusi Daya Tahan Hidup Rayleigh}

Misal $\mathrm{T}$ adalah peubah acak daya tahan hidup yang berdistribusi Rayleigh dengan parameter $\lambda$, dapat ditulis $T \sim$ Rayleigh $(\lambda)$. Fungsi kepekatan peluang dari $\mathrm{T}$ adalah

$$
f(t)=2 \lambda t \exp \left(-\lambda t^{2}\right)
$$


dengan $t, \lambda>0$.

Fungsi kumulatif dari distribusi Rayleigh,

$$
F(t)=1-\exp \left(-\lambda t^{2}\right)
$$

Fungsi survival

$$
S(t)=\exp \left(-\lambda t^{2}\right)
$$

dan fungsi hazard

$$
h(t)=2 \lambda t
$$

Rata-rata tahan hiduo dan varian distribusi Rayleigh adalah

$$
\begin{gathered}
\mu=E[T]=\lambda^{\frac{-1}{2}}\left(\frac{1}{2} \sqrt{\pi}\right) . \\
\operatorname{Var}(T)=\frac{4-\pi}{4 \lambda}
\end{gathered}
$$

\subsection{Estimasi Parameter Dari Distribusi Rayleigh dengan Metode Bayes}

Pada data daya tahan hidup disensor tipe II, percobaan akan berhenti pada $r$ kegagalan pertama dari $n$ komponen atau objek yang diuji daya tahan hidupnya dengan $1 \leqslant r \leqslant n$. Terdapat $r$ pertama observasi $t_{1}<t_{2}<\cdots<t_{r}$ yang tersedia dalam jumlah sampel berukuran $n$, sehingga fungsi kepekatan peluang bersama dari $t_{1}<t_{2}<\cdots<t_{r}$ untuk sampel disensor tipe II adalah

$$
\begin{aligned}
f\left(t_{1}, t_{2}, \cdots, t_{r}\right) & =\frac{n !}{(n-r) !}\left[S\left(t_{r}\right)\right]^{n-r} \prod_{i=1}^{r} f\left(t_{i}\right) \\
& =\frac{n !}{(n-r) !}\left[\exp \left(-\lambda t^{2}\right]^{n-r} \prod_{i=1}^{r} 2 \lambda t_{i} \exp \left(-\lambda t_{i}^{2}\right)\right. \\
& =\frac{n !}{(n-r) !}(2 \lambda)^{r} \exp \left[-\sum_{i=1}^{r} \lambda t_{i}^{2}-\left(\lambda t_{r}^{2}\right)(n-r)\right] \prod_{i=1}^{r} t_{i}
\end{aligned}
$$

Proses untuk menentukan prior Jeffrey diawali dengan menentukan fungsi likelihood untuk data disensor tipe II, sehingga:

$$
L(\lambda)=\frac{n !}{(n-r) !}(2 \lambda)^{r}\left\{\exp \left[-\left(\sum_{i=1}^{r}\left(\lambda t_{i}^{2}\right)+\left(\lambda t_{r}^{2}\right)(n-r)\right)\right]\right\} \prod_{i=1}^{r} t_{i}
$$

Logaritma natural dari fungsi likelihood adalah

$$
\ln L(\lambda)=\ln \frac{n !}{(n-r) !}+r \ln 2 \lambda-\sum_{i=1}^{r}\left(\lambda t_{i}^{2}\right)+\left(\lambda t_{r}^{2}\right)(n-r)+\sum_{i=1}^{r} \ln t_{i} .
$$


Setelah diperoleh nilai $\ln L(\lambda)$ maka kemudian ditentukan Informasi Fisher sebagai berikut:

$$
I(\lambda)=\frac{r}{\lambda^{2}}
$$

Berdasarkan informasi Fisher yang telah ditemukan sebelumnya, sehingga diperoleh distribusi prior untuk $\lambda, g(\lambda)$ adalah

$$
g(\lambda)=\frac{1}{\lambda} \sqrt{r}
$$

Distribusi posterior dari $\lambda$ adalah

$$
\begin{aligned}
f(\lambda \mid t) & =\frac{\lambda^{r-1}\left\{\exp \left[-\lambda\left(\sum_{i=1}^{r}\left(t_{i}^{2}\right)+\left(t_{r}^{2}\right)(n-r)\right)\right]\right\}}{\int_{0}^{\infty} \lambda^{r-1}\left\{\exp \left[-\lambda\left(\sum_{i=1}^{r}\left(t_{i}^{2}\right)+\left(t_{r}^{2}\right)(n-r)\right)\right]\right\} d \lambda} \\
& =\frac{\lambda^{r-1}\left[\sum_{i=1}^{r}\left(t_{i}^{2}\right)+\left(t_{r}^{2}\right)(n-r)\right]^{r}\left\{\exp \left[-\lambda\left(\sum_{i=1}^{r}\left(t_{i}^{2}\right)+\left(t_{r}^{2}\right)(n-r)\right)\right]\right\}}{\Gamma(r)}
\end{aligned}
$$

Misalkan $W=\sum_{i=1}^{r}\left(t_{i}^{2}\right)+\left(t_{r}^{2}\right)(n-r)$, maka

$$
f(\lambda \mid t)=\frac{\lambda^{r-1} W^{r} \exp (-\lambda W)}{\Gamma(r)}, \lambda>0
$$

Selanjutnya akan ditentukan mean posterior untuk parameter $\lambda_{\text {Bayes }}$, yaitu

$$
\begin{aligned}
& \widehat{\lambda}_{\text {Bayes }}=E(\lambda) \\
& \widehat{\lambda}_{\text {Bayes }}=\frac{r}{W}
\end{aligned}
$$

Diperoleh varians posterior untuk $\lambda_{\text {Bayes }}$ adalah $\frac{r}{W^{2}}$

\subsection{Studi Kasus}

Hasil yang diperoleh dari studi analitik diaplikasikan pada studi empirik dimana data sekunder yang digunakan pada studi ini berasal dari makalah oleh Lieblein dan Zelen [4]. Pada makalah tersebut diinformasikan bahwa terdapat 213 batch bearing ball hasil tes terhadap daya tahan hidup Deep - Groove bearing ball dengan data yang disensor sebanyak $r=25$, dimana $\mathrm{r}$ adalah kegagalan pertama yang terjadi. Data disensor disajikan pada tabel berikut :

Dari data endurance bearing ball diketahui bahwa $\mathrm{n}=213$ dan $\mathrm{r}=25$. Hitung nilai W terlebih dahulu :

$$
W=5812790,011
$$

Mean posterior dari $\widehat{\lambda}_{\text {Bayes }}$ adalah sebagai berikut:

$$
\begin{aligned}
\widehat{\lambda} & =\frac{r}{W} \\
& =4,3 \times 10^{-6}
\end{aligned}
$$

Rata-rata tahan hidup dari data Deep-groove bearing ball adalah

$$
\begin{aligned}
\mu & =\lambda^{\frac{-1}{2}} \Gamma\left(\frac{3}{2}\right) \\
& =427,23 .
\end{aligned}
$$


Metode Bayes Untuk Distribusi Rayleigh Pada Data Tahan Hidup Disensor Tipe II 83

\begin{tabular}{|c|c|c|c|}
\hline Nomor Bearing & Daya Tahan & Nomor Bearing & Daya Tahan \\
\hline 16 & 17,88 & 3 & 67,80 \\
10 & 28,92 & 4 & 68,64 \\
5 & 33,00 & 6 & 68,64 \\
19 & 41,52 & 25 & 68,88 \\
9 & 42,12 & 22 & 84,12 \\
11 & 45,60 & 17 & 93,12 \\
15 & 48,48 & 7 & 98,64 \\
12 & 51,84 & 23 & 105,12 \\
20 & 51,96 & 24 & 105,84 \\
18 & 54,12 & 21 & 127,92 \\
13 & 55,56 & 8 & 128,04 \\
1 & 67,80 & 14 & 173,40 \\
2 & 67,80 & & \\
\hline
\end{tabular}

Varians posterior untuk $\lambda$ adalah sebagai berikut:

$$
\begin{aligned}
\operatorname{Var}(\lambda) & =\frac{r}{W^{2}} \\
& =\frac{25}{\left(\sum_{i=1}^{25}\left(t_{i}^{2}\right)+\left(t_{25}^{2}\right)(188)\right)^{2}} .
\end{aligned}
$$

Fungsi kegagalannya (hazard) adalah sebagai berikut:

$$
\begin{aligned}
h(t) & =2 \lambda t \\
& =2\left(4,3 \times 10^{-6}\right) t .
\end{aligned}
$$

Jadi setiap komponen dengan $t$ satuan waktu akan berkurang keandalannya sebesar $h(t)$.

Fungsi survival didapatkan sebagai berikut:

$$
\begin{aligned}
S(t) & =\exp \left(-\lambda t^{2}\right) \\
& =\exp \left(-\left(4,3 \times 10^{-6}\right) t^{2}\right) .
\end{aligned}
$$

Jadi peluang komponen tersebut mampu bertahan hidup selama $t$ adalah sebesar $S(t)$.

\section{Kesimpulan}

Dapat diambil kesimpulan sebagai berikut:

(1) Estimator Bayes dari parameter berdistribusi Rayleigh untuk data disensor tipe II adalah

$$
(\widehat{\lambda})=\frac{r}{\sum_{i=1}^{r}\left(t_{i}^{2}\right)+\left(t_{r}^{2}\right)(n-r)}
$$

(2) Untuk data ketahanan hidup Deep-groove bearing ball dengan $n=213$ dan $r=$ 25 , diperoleh nilai estimator untuk $\lambda$ dari distribusi Rayleigh adalah $4,3 \times 10^{-6}$. 
Varians posterior untuk $\lambda$ adalah $\frac{25}{\sum_{i=1}^{25}\left(t_{i}^{2}\right)+\left(t_{25}^{2}\right)(188)}$, dengan fungsi hazard dari komponen yang telah diuji adalah

$$
h(t)=2\left(4,3 \times 10^{-6}\right) t
$$

dan fungsi survival dari komponen yang telah diuji adalah

$$
S(t)=\exp \left(-\left(4,3 \times 10^{-6}\right) t^{2}\right)
$$

\section{Daftar Pustaka}

[1] Bain,L.J. and Engelhardt,M. 1992. Introduction to Probability and Mathematical Statistic Second Edition. Duxbury Press, California.

[2] Berger,J.O. 1993. Statistical Decision Theory And Bayesian Analysis Second Edition.Sringer-Verlug, New York.

[3] Hossain,A.M. and Zimmer,W.J. 2003. Comparison Of Estimation Methods For Weibull Parameters: Complete and Censored Samples.J.Stat.Comput.

[4] Lieblein,J. and Zelen,M. 1956. Statistical Investigation Of The Fatigue Life Of Deep-Groove Ball Bearings. J.Res.Nst.Bureau Stand.57: 273-316.

[5] Harlan,J. 2017. Analisis Survival. Gunadarma:Depok.

[6] Sunandar, M.A. 2006. Estimasi Parameter untuk Data Waktu Hidup yang Berdistribusi Rayleigh pada Data Tersensor Tipe II Beserta Simulasinya. Skripsi. FMIPA Universitas Negeri Semarang: Semarang.

[7] Walpole, R.E., Myers, R.H., Myers, S.L and Ye, K. 2002. Probability and Statistics for Engineers and Scientist. Ninth Edition. New York: Pearson Education, Inc.

[8] Widiharih, T. dan Mardjiyati, W. 2008. Inferensi Data Uji Hidup Tersensor Tipe II Berdistribusi Rayleigh dengan Metode MLE. Media Statistika.1(2):69-74.

[9] Yanuar, F. 2015. The Use of Uninformative and Informative Prior Distribution in Bayesian. Global Journal of Pure and Applied Mathematics 11(5): 3259 3264. 